\title{
Molecular Characterization of Rifampin- and Isoniazid-Resistant Mycobacterium tuberculosis Strains Isolated in Poland
}

\author{
Anna Sajduda, ${ }^{1}$ Anna Brzostek, ${ }^{2}$ Marta Popławska, ${ }^{2}$ Ewa Augustynowicz-Kopeć, ${ }^{3}$ \\ Zofia Zwolska, ${ }^{3}$ Stefan Niemann, ${ }^{4}$ Jarosław Dziadek, ${ }^{2 *}$ \\ and Doris Hillemann ${ }^{4}$ \\ Department of Genetics of Microorganisms, University of Łódz, ${ }^{1}$ and Center for Medical Biology, \\ Polish Academy of Sciences, ${ }^{2}$ Łódź, and Department of Microbiology, National Research \\ Institute of Tuberculosis and Lung Diseases, Warsaw, ${ }^{3}$ Poland, and National Reference \\ Center for Mycobacteria, Forschungszentrum Borstel, Borstel, Germany ${ }^{4}$
}

Received 7 November 2003/Returned for modification 15 December 2003/Accepted 11 March 2004

\begin{abstract}
A total of 105 rifampin (RMP)- and/or isoniazid (INH)-resistant strains of Mycobacterium tuberculosis isolated from different parts of Poland in $\mathbf{2 0 0 0}$ were screened for mutations associated with resistance to these drugs by two molecular methods, namely sequence analysis and real-time PCR technology. Three loci associated with drug resistance were selected for characterization: they were $\operatorname{rpoB}(\mathrm{RMP}), \mathrm{kat} G$, and the regulatory region of $i n h A$ (INH). Nineteen different mutations were identified in 64 RMP-resistant strains, and five new alleles were described. The most common point mutations were in codons $531(41 \%), 516(16 \%)$, and $526(9 \%)$ of the $r p o B$ gene. Mutations were not found in two $(3 \%)$ of the isolates. In the case of resistance to INH, six different mutations in the $k a t G$ gene of 83 resistant strains were detected. Fifty-seven (69\%) isolates exhibited nucleotide substitutions at codon 315. One strain harbored a mutation affecting codon 279 (Gly279Thr). Twelve of 26 INH-resistant strains with the wild-type codon 315 (14.5\% of all strains tested) had the mutation $-15 \mathrm{C} \rightarrow \mathrm{T}$ in the regulatory region of $i n h A$. A full correlation between the DNA sequence analysis and real-time PCR data was obtained. We conclude that the real-time PCR method is fast and reliable for the detection of RMP and INH resistance-associated mutations in $M$. tuberculosis clinical isolates.
\end{abstract}

Mycobacterium tuberculosis is one of the most harmful human pathogens worldwide, causing about 8 million new tuberculosis (TB) cases and between 2 million and 3 million deaths yearly (29). The upsurge of TB has been accompanied by a rise in the frequency of $M$. tuberculosis strains that are resistant to one or more primary anti-TB drugs. In Poland, 10,049 new and 1,428 previously treated TB cases were reported in 2000 (notification rate, 29.7 of 100,000). Primary drug resistance has been monitored since 1960, with decreasing frequencies occurring up to 1997. In 2000, a twofold increase in the primary resistance rate was observed in comparison with that in 1997 (6.1 versus $3.6 \%)$ (1). At the same time, an increased level of primary multidrug resistance (MDR) (resistance to at least isoniazid $[\mathrm{INH}]$ and rifampin [RMP]) was also observed (1.2 versus $0.6 \%$ ) (1).

Early diagnosis of the disease and the rapid identification of resistance to primary anti-TB agents are essential for the efficient treatment and control of MDR strains. It is known that resistance to INH and RMP is a key factor in determining the effectiveness of the currently recommended standard treatment regimens. The elucidation of the mechanism of action of these drugs, which was accomplished only recently, has led to the development of new rapid diagnostic methods $(4,7,14,19$, 22).

The rapid detection of RMP resistance is of particular im-

\footnotetext{
* Corresponding author. Mailing address: Center for Medical Biology, Polish Academy of Sciences, Lodowa 106, 93-232 Łódź, Poland. Phone: 4842 6771250. Fax: 4842 6771230. E-mail: jdziadek@cmiwpan .lodz.pl.
}

portance, since it also represents a valuable surrogate marker for MDR resistance, which is a tremendous obstacle to TB therapy (10). Collectively, DNA sequencing studies have demonstrated that $>95 \%$ of RMP-resistant $\left(\mathrm{Rmp}^{\mathrm{r}}\right)$ M. tuberculosis strains have a mutation within the 81-bp hot-spot region (codons 507 to 533) of the RNA polymerase $\beta$ subunit (rpoB) gene (23). The prevalence of the mutations determined so far varies for $M$. tuberculosis strains obtained from different countries. Thus, it is important to determine the distribution of resistance mutations at the level of each country prior to molecular tests being introduced for routine diagnostics (4).

Unlike RMP resistance, INH resistance is apparently controlled by a more complex genetic system that involves several genes (21). However, extensive studies have demonstrated that INH resistance is most frequently associated with a specific mutation in katG (codon 315), a gene that encodes the catalase-peroxidase enzyme in M. tuberculosis (18). Also, InhA (enoyl-ACP-reductase), an enzyme involved in mycolic acid biosynthesis, was identified as a main target of INH, and mutations in the regulatory region of the $\operatorname{inh} A$ gene have been linked to INH resistance (12).

The aim of the present study was to determine the drug resistance profiles of 105 drug-resistant $M$. tuberculosis strains isolated in Poland and to detect mutations present in the rpoB and $k a t G$ genes as well as in the regulatory region of the inh $A$ gene. Two molecular methods were used. In the first one, mutations that have been associated with RMP and/or INH resistance were determined by automated DNA sequence analysis. The results were compared with those obtained by real-time PCR technology. 
TABLE 1. Primers and probes used for PCR amplification and detection of drug-resistant M. tuberculosis strains

\begin{tabular}{|c|c|c|c|c|c|c|}
\hline Target & Primer or probe & Sequence $\left(5^{\prime}-3^{\prime}\right)^{h}$ & $\begin{array}{c}\text { Nucleotides } \\
\text { within } \\
\text { target }^{a}\end{array}$ & $\begin{array}{l}\text { Product } \\
\text { size (bp) }\end{array}$ & $\begin{array}{l}\text { Annealing } \\
\text { temp }\left({ }^{\circ} \mathrm{C}\right)\end{array}$ & $T_{m}\left({ }^{\circ} \mathrm{C}\right)$ \\
\hline \multirow[t]{6}{*}{ rрoB } & TR9 & TCGCCGCGATCAAGGAGT $^{b}$ & $2335-2352$ & \multirow[t]{6}{*}{158} & \multirow[t]{6}{*}{62} & 61.0 \\
\hline & TR8 & GTGCACGTCGCGGACCTCCA $^{b}$ & $2492-2473$ & & & 68.4 \\
\hline & rpo sensor ${ }^{c}$ & 640-ACCCACAAGCGCCGACTGCTGG-P ${ }^{d}$ & $2412-2432$ & & & 70.4 \\
\hline & rpo anchor ${ }^{c}$ & TTCATGGACCAGAACAACCCGCTGTCGGT-F & 2379-2407 & & & 73.8 \\
\hline & RPO1 sensor ${ }^{e}$ & CAGCTGAGCCAATTCATGGACC-F & $2367-2388$ & & & 65.2 \\
\hline & RPO1 sensor ${ }^{e}$ & 640-AACAACCCGCTGTCGGGG & $2390-2407$ & & & 65.2 \\
\hline \multirow[t]{7}{*}{$k a t G$} & TB86 & GAAACAGCGGCGCTGATCGT $^{b}$ & $2759-2778$ & \multirow[t]{7}{*}{209} & \multirow[t]{7}{*}{67} & 64.3 \\
\hline & TB87 & GTTGTCCCATTTCGTCGGGG $^{b}$ & 2968-2948 & & & 62.8 \\
\hline & TB sensor ${ }^{c}$ & 640-TCACCAGCGGCATCGAGGTCGT-P ${ }^{d}$ & 2916-1937 & & & 69.4 \\
\hline & TB anchor ${ }^{c}$ & CGTATGGCACCGGAACCGGTAAGGACGC-F & $2886-2913$ & & & 75.3 \\
\hline & TaqMan MGB probes & FAM-ACCAGCGGCATCG-Q & 2918-2930 & & & 66.3 \\
\hline & & VIC-TCACCACAGGCATCG-Q & $2916-2930$ & & & 65.1 \\
\hline & & VIC-ACCACCGGCATCG-Q & $2918-2930$ & & & 64.9 \\
\hline \multirow[t]{4}{*}{$\operatorname{inh} A$} & TB92 & CCTCGCTGCCCAGAAAGGGA ${ }^{f}$ & $56-75$ & \multirow[t]{4}{*}{248} & \multirow[t]{4}{*}{64} & 65.2 \\
\hline & TB93 & ATCCCCCGGTTTCCTCCGGT ${ }^{f}$ & $303-284$ & & & 66.5 \\
\hline & TB ATT $^{g}$ & 640-CCCGACAACCTATCATCTCGCC-P ${ }^{d}$ & 223-202 & & & 63.1 \\
\hline & TB anchor ${ }^{g}$ & CCCCTTCAGTGGCTGTGGCAGTC-F & $248-226$ & & & 68.1 \\
\hline
\end{tabular}

${ }^{a}$ The positions of the primers and probes correspond to GenBank accession numbers L27989, X68081, and U66801 for the rpoB gene, the katG gene, and the inhA locus, respectively.

${ }^{b}$ Primer sequence described by Telenti et al. (23).

${ }^{c}$ Probe sequence described by Torres et al. (25).

${ }^{d} \mathrm{P}$, phosphorylation of the $3^{\prime}$ end of the probe to prevent extension during PCR.

${ }^{e}$ Probe sequence described by Garcia de Viedma et al. (7).

${ }^{f}$ Primer sequence described by Gonzalez et al. (8).

${ }^{g}$ Probe sequence described by Torres et al. (26)

${ }^{h}$ Fluorophores were as follows: 640, Red 640; F, fluorescein; FAM, 6-carboxy-fluorescein; Q, quencher (TAMRA [6-carboxy- $N, N, N^{\prime}, N^{\prime}$-tetramethylrhodamine]); VIC, fluorescent reporter. For TaqMan MGB probes, designed to detect wt codon 315 of katG (AGC) and two mutations (ACA and ACC), these sequences are underlined.

\section{MATERIALS AND METHODS}

Bacterial strains. The $M$. tuberculosis strains examined for this study were isolated from TB patients in Poland in 2000 during the second national survey of drug resistance. Strains obtained in different regions of the country were provided by the National Tuberculosis Reference Laboratory in Warsaw. In this survey, 221 INH-resistant $\left(\mathrm{Inh}^{\mathrm{r}}\right)$ and $104 \mathrm{Rmp}^{\mathrm{r}}$ strains were identified [both monoresistant and multiply resistant to another drug(s)] (1). Of these, 105 drug-resistant $M$. tuberculosis strains were examined, comprising $83 \operatorname{Inh}^{\mathrm{r}}(37.6 \%)$ and $64 \mathrm{Rmp}^{\mathrm{r}}(61.5 \%)$ strains (numbers include 59 MDR strains). As controls, $M$. tuberculosis strain H37Rv (susceptible) and four INH-sensitive and three RMPsensitive clinical isolates were included for the analysis.

Primary isolation, differentiation, and drug susceptibility testing were performed with Löwenstein-Jensen medium and the BACTEC 460-TB system (Becton-Dickinson, Sparks, Md.), as reported earlier (1).

The relatedness of all resistant strains was investigated by studying restriction fragment length polymorphisms (RFLPs) of the IS6110 element (28). The spoligotyping (spacer oligotyping) method (11) was additionally used to confirm the relationships of the strains.

DNA preparation. A rapid DNA extraction procedure for the direct testing of M. tuberculosis on Löwenstein-Jensen slants was performed. A loopful of organisms was suspended in $1 \mathrm{ml}$ of sterile water and the bacteria were lysed by boiling for $20 \mathrm{~min}$. The cells were centrifuged $(12,000 \times g$ for $5 \mathrm{~min})$ and then frozen overnight at $-20^{\circ} \mathrm{C}$. The supernatant was used as a template for amplification.

Standard PCR. The DNA extract was amplified with the primers listed in Table 1. Primer pairs TR8-TR9 and TB86-TB87 were used to amplify the regions within the $r p o B$ and $k a t G$ genes, respectively (22). Primers TB92 and TB93 were applied for the amplification of a fragment containing the regulatory region of the inh $A$ locus (8). Prior to PCR, a preincubation step $\left(95^{\circ} \mathrm{C}\right.$ for $\left.15 \mathrm{~min}\right)$ was performed to activate the HotStart Taq DNA polymerase (Qiagen $\mathrm{GmbH}$ Hilden, Germany). The PCR was carried out for 35 cycles of denaturation at $94^{\circ} \mathrm{C}$ for $30 \mathrm{~s}$, annealing at $62^{\circ} \mathrm{C}$ (for $r p o B$ ), $67^{\circ} \mathrm{C}$ (for kat G), or $64^{\circ} \mathrm{C}$ (for inh $A$ ) for $30 \mathrm{~s}$, and extension at $72^{\circ} \mathrm{C}$ for $45 \mathrm{~s}$ in an MJ Research thermocycler. PCR products were examined by gel electrophoresis and purified by use of a QIAquick PCR purification kit (Qiagen).

DNA sequence analysis. The PCR primers were also used for the direct sequencing of both strands of the amplification products with an automated ABI Prism 377 DNA sequencer and corresponding kits from the same manufacturer
(Applied Biosystems, Foster City, Calif.). The Blast 2 Sequences computer program was used for DNA sequence comparisons (http://www.ncbi.nlm.nih.gov/ BLAST/).

Probes for detection of mutations by real-time PCR. The sequences of the probes used for the present study are listed in Table 1. For the detection of mutations in the $r p o B$ gene, two pairs of fluorescence resonance energy transfer (FRET) probes, the rpo (25) and RPO1 (7) probes, were used. Both pairs of probes were labeled with fluorescein (at the $3^{\prime}$ ends) and Red 640 (at the $5^{\prime}$ ends) and were homologous to the wild-type (wt) sequence. Thus, mutations in the DNA region covered by the probes led to different melting temperatures $\left(T_{m} \mathrm{~s}\right)$ for the probes when they were hybridized to the target.

For $k a t G$, a set of standard FRET probes and three TaqMan minor groove binder (MGB) probes were applied. The FRET probes covered the region containing codon 315 , which is the most frequent target for mutations related to INH resistance. This pair of probes was labeled with fluorescein (TB anchor) and Red 640 (TB sensor) (25). Additionally, three katG-specific TaqMan MGB probes were designed to be homologous to wt codon 315 (AGC) or to one of the most frequent substitutions, ACC or ACA. These oligonucleotides contained a reporting fluorescent dye (FAM or VIC) at the $5^{\prime}$ end and a quencher dye (TAMRA) at the $3^{\prime}$ end. During PCR, the $5^{\prime} \rightarrow 3^{\prime}$ exonuclease activity of Taq DNA polymerase cleaves the downstream probe as it extends. As the probe is degraded, the reporter dye is separated from the quencher. This results in increased fluorescence as amplification proceeds. Because the cleavage occurs only if the probe hybridizes to the target, the fluorescence detected originates from specific amplification.

For the detection of mutations in the inhA locus, a pair of conventional FRET probes was used (anchor-sensor design) (26). The 5'-Red 640-labeled sensor (TB ATT) covered the segment containing the regulatory region (Table 1).

All primers and FRET probes were synthesized by TIB MOLBIOL (DNA Synthesis Service, Berlin, Germany), and TaqMan MGB probes were synthesized by Applied Biosystems (Weiterstadt, Germany).

Real-time PCR assay. The PCR mixtures, in a final volume of $20 \mu \mathrm{l}$, contained $2.5 \mathrm{mM} \mathrm{MgCl}_{2}$, a $200 \mu \mathrm{M}$ concentration of each deoxynucleoside triphosphate, a $1 \mu \mathrm{M}$ concentration of each primer, a $0.2 \mu \mathrm{M}$ concentration of each probe (except for the RPO1 and TaqMan MGB probes, which were added to final concentrations of 0.04 and $0.1 \mu \mathrm{M}$, respectively), $1 \mathrm{U}$ of HotStart Taq DNA polymerase (Qiagen), and $2 \mu \mathrm{l}$ of template DNA. Additionally, the reaction 
TABLE 2. DNA sequencing and real-time PCR data for $r p o B$ mutations in $\mathrm{Rmp}^{\mathrm{r}}$ M. tuberculosis strains from Poland

\begin{tabular}{|c|c|c|c|c|c|}
\hline \multirow[b]{2}{*}{$\begin{array}{l}\text { Affected } \\
\text { codon }\end{array}$} & \multirow[b]{2}{*}{ Nucleotide change(s) } & \multirow[b]{2}{*}{ Amino acid change } & \multirow{2}{*}{$\begin{array}{l}\text { No. }(\%) \\
\text { of strains } \\
\text { with } \\
\text { mutation }\end{array}$} & \multicolumn{2}{|c|}{ Deviation of $T_{m}\left({ }^{\circ} \mathrm{C}\right)$ from that for $\mathrm{wt}^{a}$} \\
\hline & & & & $\begin{array}{l}\text { RPO1 probe } \\
\left(65.4^{\circ} \mathrm{C}\right)\end{array}$ & $\begin{array}{c}\text { rpo probe } \\
\left(63.2^{\circ} \mathrm{C}\right)\end{array}$ \\
\hline \multirow{2}{*}{531} & $\mathrm{TCG} \rightarrow \mathrm{TTG}$ & $\mathrm{Ser} \rightarrow$ Leu & $24(37.5)$ & & +1.92 to +2.62 \\
\hline & $\mathrm{TCG} \rightarrow \mathrm{TGG}$ & $\mathrm{Ser} \rightarrow \operatorname{Trp}$ & $2(3.1)$ & & ND \\
\hline \multirow{4}{*}{526} & $\mathrm{CAC} \rightarrow \mathrm{ACC}$ & $\mathrm{His} \rightarrow \mathrm{Thr}$ & $2(3.1)$ & & -1.78 \\
\hline & $\mathrm{CAC} \rightarrow \mathrm{GAC}$ & His $\rightarrow$ Asp & $2(3.1)$ & & -3.08 to -3.38 \\
\hline & $\mathrm{CAC} \rightarrow \mathrm{TGC}$ & $\mathrm{His} \rightarrow \mathrm{Cys}$ & $1(1.6)$ & & ND \\
\hline & $\mathrm{CAC} \rightarrow \mathrm{TAC}$ & $\mathrm{His} \rightarrow \mathrm{Tyr}$ & $1(1.6)$ & & -1.78 \\
\hline 522 & $\mathrm{TCG} \rightarrow \mathrm{TTG}$ & $\mathrm{Ser} \rightarrow \mathrm{Leu}$ & $1(1.6)$ & ND & \\
\hline 517 & $\mathrm{CAA} \rightarrow \mathrm{CTA}^{b}$ & $\mathrm{Gln} \rightarrow \mathrm{Leu}$ & $1(1.6)$ & -3.83 & \\
\hline \multirow[t]{3}{*}{516} & $\mathrm{GAC} \rightarrow \mathrm{TAC}$ & Asp $\rightarrow$ Tyr & $6(9.4)$ & -2.33 to -2.83 & \\
\hline & $\mathrm{GAC} \rightarrow \mathrm{GTC}$ & $\mathrm{Asp} \rightarrow \mathrm{Val}$ & $3(4.7)$ & -2.53 & \\
\hline & $\mathrm{GAC} \rightarrow \mathrm{GTG}^{b}$ & $\mathrm{Asp} \rightarrow \mathrm{Val}$ & $1(1.6)$ & -2.83 & \\
\hline \multirow[t]{2}{*}{513} & $\mathrm{CAA} \rightarrow \mathrm{CTA}$ & $\mathrm{Gln} \rightarrow \mathrm{Leu}$ & $2(3.1)$ & -3.83 & \\
\hline & $\mathrm{CAA} \rightarrow \mathrm{AAA}$ & $\mathrm{Gln} \rightarrow$ Lys & $2(3.1)$ & -6.33 & \\
\hline 514 & TTC & Phe (Ins) ${ }^{c}$ & $1(1.6)$ & -5.33 & \\
\hline 516 and 529 & $\mathrm{GAC} \rightarrow \mathrm{GGC}$ and $\mathrm{CGA} \rightarrow \mathrm{CAA}$ & $\mathrm{Asp} \rightarrow$ Gly and $\mathrm{Arg} \rightarrow$ Gln & $1(1.6)$ & ND & \\
\hline 515 and 516 & $\mathrm{ATG} \rightarrow \mathrm{ATT}^{b}$ and $\mathrm{GAC} \rightarrow \mathrm{TAC}$ & Met $\rightarrow$ Ile and Asp $\rightarrow$ Tyr & $8(12.5)$ & -6.33 to -6.63 & \\
\hline 513 and 526 & $\mathrm{CAA} \rightarrow \mathrm{CTA}$ and $\mathrm{CAC} \rightarrow \mathrm{AAC}$ & Gln $\rightarrow$ Leu and His $\rightarrow$ Asn & $1(1.6)$ & ND & \\
\hline 512 and 516 & $\mathrm{AGC} \rightarrow \mathrm{ATC}^{b}$ and $\mathrm{GAC} \rightarrow \mathrm{GGC}$ & Ser $\rightarrow$ Ile and Asp $\rightarrow$ Gly & $1(1.6)$ & -7.33 & \\
\hline 510 and 516 & $\mathrm{CAG} \rightarrow \mathrm{CAC}^{b}$ and $\mathrm{GAC} \rightarrow \mathrm{TAC}$ & $\mathrm{Gln} \rightarrow \mathrm{His}$ and Asp $\rightarrow \mathrm{Tyr}$ & $2(3.1)$ & -6.33 & \\
\hline None & None & None (wt) & $2(3.1)$ & -0.13 to -0.17 & \\
\hline
\end{tabular}

${ }^{a}$ Deviations in the $T_{m}$ s for the RPO1 (7) and $r p o$ (25) probes in comparison with the value for the reference wt sequence (given in parentheses); ND, not determined.

${ }^{b}$ New allele.

${ }^{c}$ Ins, insertion.

mixture for $r p o B$ amplification included $8 \mu$ l of Q solution (Qiagen). For preparation of the components for the $k a t G$ gene PCR with TaqMan MGB probes, $10 \mu \mathrm{l}$ of a commercial ready-to-use reaction mix (universal PCR master mix; Roche) was used.

The cycling parameters used for experiments with FRET probes were as follows: $95^{\circ} \mathrm{C}$ for $10 \mathrm{~min}$ and 35 to 40 amplification cycles at $94^{\circ} \mathrm{C}$ for $15 \mathrm{~s} ; 62,67$, or $64^{\circ} \mathrm{C}$ (annealing temperatures for $r p o B, k a t G$, and inh $A$, respectively) for $20 \mathrm{~s}$; and $72^{\circ} \mathrm{C}$ for $30 \mathrm{~s}$. PCR cycling was followed by a melting-curve analysis from 50 to $85^{\circ} \mathrm{C}$, with fluorescence readings taken every $1^{\circ} \mathrm{C}$. The $T_{m}$ of each of the FRET probes for the wt sequence was calculated empirically as the average value of the $T_{m}$ s obtained in at least three independent experiments. When a probe binds to a mismatched sequence, the $T_{m}$ deviates with respect to that of a perfectly matched wt sequence. The standard deviations (SD) of the $T_{m} \mathrm{~s}$ for probes $r p o$, RPO1, TB $(k a t G)$, and TB $(i n h A)$ were $0.10,0.33,1.20$, and $0.36^{\circ} \mathrm{C}$. In all cases in which the deviations in the $T_{m}$ were more than two times the $\mathrm{SD}$, a mutation was suspected.

For PCRs with TaqMan MGB probes, the conditions for cycling were $94^{\circ} \mathrm{C}$ for $10 \mathrm{~min}$ followed by 40 to 45 cycles of $92^{\circ} \mathrm{C}$ for $15 \mathrm{~s}$ and $60^{\circ} \mathrm{C}$ for $1 \mathrm{~min}$. All reactions were performed in a Rotor-Gene 2000 instrument (Corbett Research, Mortlake, Australia).

\section{RESULTS}

Detection of mutations in the $r p o B$ gene. Sixty-four $\operatorname{Rmp}^{\mathrm{r}} M$. tuberculosis clinical isolates (including 59 MDR strains) were subjected to DNA sequencing analysis of the hypervariable (hot-spot) $r p o B$ region. Nineteen different types of mutations were identified (Table 2). Most of them were single-nucleotide mutations (69\%) involving six codons. No silent substitutions in the 158-bp rрoB gene fragment examined were observed for any of the $M$. tuberculosis strains analyzed in this study. The codons most frequently affected by point mutations were codons 531, 516, and 526, with frequencies of 41,16 , and $9 \%$, respectively. Eighteen strains $(28 \%)$ exhibited more complex mutations. One strain, identified as a member of the Beijing family, had an insertion of Phe between codons 514 and 515. Thirteen $\mathrm{Rmp}^{\mathrm{r}}$ strains of $M$. tuberculosis $(20 \%)$ contained point mutations in two separate codons, specifically in codons
513 and $526(1.6 \%), 516$ and $529(1.6 \%), 512$ and $516(1.6 \%)$, 510 and $516(3.1 \%)$, and 515 and $516(12.5 \%)$. The last three double mutations have not been described previously. The most frequent of them (Met515Ile plus Asp516Tyr) was found in eight strains. Seven of these isolates had identical IS6110 RFLP patterns, indicating their epidemiologic relationship. However, direct epidemiologic links could be established for only two patients of this cluster. Additionally, two strains had novel mutations in single codons. One of these two strains contained a GAC $\rightarrow$ GTG (Asp-to-Val) mutation in codon 516, and in the other strain codon 517 had the mutation $\mathrm{CAA} \rightarrow$ CTA (Gln to Leu). In total, five new alleles were identified in the present study, with all involving changes in one or two codons. Two Rmp ${ }^{\mathrm{r}}$ strains $(3.1 \%)$ contained no mutations in the sequenced region, although these strains were phenotypically resistant to RMP. None of the three RMP-sensitive control isolates had any mutation.

Fifty-eight $\mathrm{Rmp}^{\mathrm{r}}$ strains (including $55 \mathrm{MDR}$ isolates) that were previously characterized by DNA sequencing and three RMP-susceptible clinical isolates were available for analysis by the faster technology of real-time PCR. The three susceptible strains showed $T_{m}$ s within the range obtained for the wt reference strain M. tuberculosis H37Rv. All strains with a changed $r p o B$ core region were correctly identified in the real-time PCR assay. With the rpo sensor probe (25), a change from the wt sequence to a sequence with a mutation at codon 531 $(\mathrm{TCG} \rightarrow \mathrm{TTG})$ was detected in 24 strains as an increase in the $T_{m}$ of the probe (from 1.92 to $2.62^{\circ} \mathrm{C}$; Table 2), whereas for the 5 strains with three different mutations at codon 526 , the $T_{m}$ of the probe was 1.78 to $3.38^{\circ} \mathrm{C}$ lower (depending on the mutation) than that of the wt strain (Table 2). With the RPO1 probes (7), mutations in the $5^{\prime}$ half of the core in 29 strains were also detected by reductions in the $T_{m}$ s of the probes 
TABLE 3. DNA sequencing and real-time PCR data for mutations in the $k a t G$ gene and the $i n h A$ regulatory region in Inh ${ }^{\mathrm{r}} M$. tuberculosis strains from Poland

\begin{tabular}{|c|c|c|c|c|c|c|c|c|}
\hline \multirow{2}{*}{ DNA target } & \multirow{2}{*}{$\begin{array}{l}\text { No. of strains } \\
\text { tested }\end{array}$} & \multirow{2}{*}{$\begin{array}{l}\text { Nucleotide } \\
\text { change(s) }\end{array}$} & \multirow{2}{*}{$\begin{array}{l}\text { Amino acid } \\
\text { change }\end{array}$} & \multirow{2}{*}{$\begin{array}{l}\text { No. }(\%) \\
\text { of strains } \\
\text { with } \\
\text { mutation }\end{array}$} & \multirow{2}{*}{$\begin{array}{c}\text { Deviation of } T_{m} \\
\left({ }^{\circ} \mathrm{C}\right) \text { from that } \\
\text { for wt for FRET } \\
\text { probes }^{a}\end{array}$} & \multicolumn{3}{|c|}{ Result with TaqMan MGB probe } \\
\hline & & & & & & ACC & ACA & $\mathrm{AGC}(\mathrm{wt})$ \\
\hline \multirow[t]{5}{*}{ kat $G$ codon 315} & 83 & $\mathrm{AGC} \rightarrow \mathrm{ACC}$ & $\mathrm{Ser} \rightarrow \mathrm{Thr}$ & $50(60.2)$ & -2.41 to -4.41 & + & - & - \\
\hline & & $\mathrm{AGC} \rightarrow \mathrm{ACT}$ & $\mathrm{Ser} \rightarrow \mathrm{Thr}$ & $4(4.8)$ & -8.51 & - & - & - \\
\hline & & $\mathrm{AGC} \rightarrow \mathrm{ACA}$ & $\mathrm{Ser} \rightarrow \mathrm{Thr}$ & $1(1.2)$ & -8.41 & - & + & - \\
\hline & & $\mathrm{AGC} \rightarrow \mathrm{AAC}$ & $\mathrm{Ser} \rightarrow$ Asn & $1(1.2)$ & -4.71 & - & - & - \\
\hline & & $\mathrm{AGC} \rightarrow \mathrm{ATC}$ & $\mathrm{Ser} \rightarrow \mathrm{Ile}$ & $1(1.2)$ & -3.21 & - & - & - \\
\hline \multirow[t]{2}{*}{ kat $G$ codon 279} & & $\mathrm{GGC} \rightarrow \mathrm{ACC}$ & $\mathrm{Gly} \rightarrow \mathrm{Thr}$ & $1(1.2)$ & +0.29 & - & - & + \\
\hline & & None & None (wt) & $25(30.1)$ & -1.71 to +1.09 & - & - & + \\
\hline \multirow[t]{2}{*}{$\operatorname{inh} A$} & $26^{c}$ & $-15 \mathrm{C} \rightarrow \mathrm{T}$ & & $12(14.5)$ & +4.85 to +5.25 & & & \\
\hline & & None & & $14(16.5)$ & -0.45 to +0.55 & & & \\
\hline kat $G$ and inh $A$ & $83^{d}$ & None & None (wt) & $13(15.7)$ & & & & \\
\hline
\end{tabular}

${ }^{a}$ Deviations in the $T_{m}$ s for the $k a t G(25)$ - and $i n h A(26)$-specific probes in comparison with the value for the reference wt sequence (74.8 and $62.1^{\circ} \mathrm{C}$, respectively).

${ }^{b}$ Three different probes were designed to detect mutations ACC and ACA and the AGC wt sequence in kat $G$ codon 315 . + , positive result; -, negative result.

${ }^{c}$ The strains had a wt codon 315 in the $k a t G$ gene.

${ }^{d}$ All Inh $^{\mathrm{r}}$ strains were included.

(from -2.33 to $-7.33^{\circ} \mathrm{C}$; Table 2 ). The real-time PCR assay results were in full accordance with the nucleotide sequencing data.

Detection of mutations in the $\boldsymbol{k a t} \boldsymbol{G}$ gene. Eighty-three $M$. tuberculosis strains that were resistant to INH [alone or in combination with another $\operatorname{drug}(\mathrm{s})]$ were investigated by DNA sequencing of a 209-bp kat $G$ fragment including codon 315, the codon at which mutations are most frequently associated with INH resistance. Fifty-seven $(68.7 \%) \mathrm{Inh}^{\mathrm{r}}$ isolates had mutations at codon 315 (Table 3). The wt codon, AGC (Ser), was altered to ACC (Thr) in 50 strains, ACT (Thr) in 4 strains, ACA (Thr) in 1 strain, AAC (Asn) in 1 strain, and ATC (Ile) in 1 strain. One strain harbored a double mutation affecting codon 279 (GGC $\rightarrow$ ACC [Gly $\rightarrow$ Thr] $)$. In 25 (30.1\%) cases, no mutation was found in the analyzed fragment. Four INH-susceptible control isolates possessed the wt sequence.

All 83 Inh $^{\mathrm{r}}$ strains and 4 INH-sensitive controls were subjected to real-time PCR analysis, and the results were compared to those obtained by DNA sequencing. Two different types of probes (FRET and TaqMan MGB) were used to detect the most prevalent mutations associated with INH resistance. The analysis (Table 3 ) indicated the presence of deviations in the $T_{m}$ s of the FRET probes specific for kat $G$ (25), which suggests the presence of mutations, for all 57 strains $\left(T_{m}\right.$ reductions, -2.41 to $-8.51^{\circ} \mathrm{C}$ ). For the four $\mathrm{INH}$-sensitive isolates, the $T_{m}$ s of the probes were within the range of the SD for the wt reference strain. A mutation at codon 279 in one strain could not be detected because it was outside the region spanned by the probe used. A similar result for this strain was obtained with three different TaqMan MGB probes designed to detect wt codon 315 (AGC) and its two most frequent mutations, ACC and ACA. All ACC and ACA mutations in codon 315 as well as the wt AGC sequence were correctly identified by the TaqMan MGB probes (Table 3). Only three other substitutions at codon 315 (ACT, AAC, and ATC) were not detected by these particular probes. Overall, except for four explainable cases, there was full agreement between the results of real-time PCR and those of sequencing, both according to the presence or absence of mutations (FRET and Taq-
Man MGB probes) and according to the presence of two particular mutations for $\operatorname{Inh}^{\mathrm{r}}$ (TaqMan MGB assay).

Detection of mutations in the inh $A$ regulatory region. Twenty-six $\operatorname{Inh}^{\mathrm{r}} M$. tuberculosis strains that had no mutations at $\mathrm{katG}$ codon 315 (including one strain carrying a mutation at codon 279) were investigated in a real-time PCR test. A set of standard FRET probes was used to detect changes in a 22-bp fragment upstream of the start site of $i n h A$ (26). For 4 INHsusceptible control isolates and $14 \mathrm{Inh}^{\mathrm{r}}$ strains (including one strain with a mutation at codon 279 of $k a t G$ ), the $T_{m}$ s were within the range obtained for the reference strain, and therefore they were not considered mutants (Table 3). For the remaining $12(14.5 \%) \operatorname{Inh}^{\mathrm{r}}$ strains, deviations in the $T_{m} \mathrm{~s}$ of the probes suggested mismatches, as there were increases in the $T_{m}$ s of the probes (from 4.85 to $5.25^{\circ} \mathrm{C}$; Table 3 ) compared to those for the wt reference strain.

To confirm the alterations in the inh $A$ regulatory region in the $12 \mathrm{Inh}^{\mathrm{r}}$ strains, we determined the DNA sequence of the 248-bp fragment of this locus. We found that all of the strains carried a single point mutation, $\mathrm{C} \rightarrow \mathrm{T}$, at position 15 upstream of the start site of the inhA gene (Table 3). This mutation has previously been reported by other groups. The present understanding of this mutation is that it probably confers resistance by a drug titration effect. Overall, 58 (69.9\%) $\operatorname{Inh}^{\mathrm{r}}$ M. tuberculosis strains investigated in this study harbored mutations in the kat $G$ gene, $12(14.5 \%)$ strains carried a mutation in the regulatory region of the $i n h A$ gene, and the remaining $13(15.7 \%)$ isolates had no detectable changes in the two targets analyzed. In all cases, full concordance was obtained between the realtime PCR results and DNA sequencing data.

DNA fingerprinting analysis. Two standardized DNA fingerprinting techniques, spoligotyping (11) and IS6110 RFLP typing (28), were used to differentiate the strains in order to assess possible genetic similarities between them. The numbers of IS6110 copies per isolate varied from 5 to 20 (A. Sajduda, A. Brzostek, and J. Dziadek, unpublished results). A total of 73 different IS6110 fingerprint patterns were identified for the 105 analyzed strains. Fifty-nine strains showed unique fingerprints, which indicates their epidemiologic independence. However, 
46 strains $(44 \%)$ clustered into 14 groups consisting of two to seven isolates with identical IS6110 RFLP patterns, representing possible cases of recent transmission. Direct epidemiologic links could not be established for most of the cases in clusters. However, the transmission of the same drug-resistant $M$. tuberculosis strain among the patients of one cluster or their infection by contact with one or more index patients is further supported by the observation that in most clusters all of the strains exhibited the same polymorphism in the $\mathrm{Rmp}^{\mathrm{r}}$ and/or $\mathrm{Inh}^{\mathrm{r}}$-associated genes and identical or very similar drug resistance profiles (data not shown). Also, only five of the clusters had isolates with different $\mathrm{Rmp}^{\mathrm{r}}$ and/or $\mathrm{Inh}^{\mathrm{r}}$ mutations, indicating an independent acquirement of resistance to these drugs. Although the epidemiologic data obtained in the present study are preliminary, they show that the transmission of drug-resistant $M$. tuberculosis strains may have occurred in Poland and seems to have contributed to the emergence of drug-resistant TB in this country.

\section{DISCUSSION}

In this study, a total of $105 \operatorname{Inh}^{\mathrm{r}}$ and/or Rmp ${ }^{\mathrm{r}}$ M. tuberculosis strains, isolated in Poland in 2000 during the second national drug resistance survey, were investigated by DNA sequencing and a real-time PCR assay to evaluate drug resistance mechanisms.

Our findings of mutations in the rpoB and $k a t G$ genes were comparable to those reported for strains from other parts of the world, especially the common mutations, which reflect a global pattern (16). The rpoB codons 531, 526, and 516 are the most frequently mutated codons worldwide, although variations in the relative frequencies of mutations in these codons have been described for $M$. tuberculosis isolates from different geographic locations (reviewed in reference 4). Also, in our study most of the strains with the $\mathrm{Rmp}^{\mathrm{r}}$ phenotype (69\%) contained missense mutations which led to amino acid substitutions at the Ser531 (41\%), Asp516 (16\%), and His526 (9\%) residues. A comparison of these results with the results of other studies showed that the mutations at codon 531 also predominate in Poland $(4,23,27)$. In contrast with previously published data, the frequency of mutations at codon 516 was found to be high in Poland $(4,23)$. A high frequency of changes at this codon was also described recently for MDR M. tuberculosis isolates from East Hungary (3), Latvia (27), North India (20), and East Asia (15). A characteristic finding was the high frequency of double mutations occurring in two separate codons $(20 \%)$. Altogether, we found five novel alleles, which broadens the range of known mutations in the $r p o B$ gene. The high incidence of these less common changes in Polish strains can be explained by either geographic variations in the frequencies of particular $r p o B$ mutations or a sample bias. Sequence analysis identified no mutation in two $(3.1 \%)$ of the strains tested, although they were resistant to RMP as determined by the proportion method. A recent study revealed that a mutation associated with RMP resistance can also be located outside the 81-bp rpoB core region, although this does not occur frequently (9). Other possibilities are that in these resistant strains, other rare $r p o B$ mutations, heteroresistance (a mixture of susceptible and resistant subpopulations), or less likely, another mechanism of resistance may be involved (3, 10).

In Inh $^{\mathrm{r}}$ strains, neither insertions nor deletions (complete or partial) of kat $\mathrm{G}$ were found, which is evidence of the rare occurrence of these mutations in clinical isolates, although they were reported previously by other authors $(20,24)$. We observed that almost $70 \%$ of the strains studied carried the Ser315Thr substitution, which is in concordance with the bulk of the published data (16). However, the frequency of this mutation was lower in Polish strains than the $93.6 \%$ of strains in northwestern Russia (13), 91\% of strains in Latvia (26), and $85.7 \%$ of strains in Lithuania (2). In accordance with previous reports, the most frequent mutation was AGC to ACC at kat codon $315(60 \%)$. A novel double mutation, AGC to ACT, which also leads to an amino acid change from Ser to Thr, was found in four strains. However, three of these isolates seemed to be epidemiologically related, according to their identical patterns in the IS6110 RFLP analysis. We also identified one strain with a double mutation at codon 279 (GGC $\rightarrow$ ACC) that has not been described previously. This strain carried wt kat $G$ codon 315 and showed no mutation in the regulatory region of $\operatorname{inh} A$ (see below). We assume that this mutation is involved in the INH resistance of this strain.

Since $31 \%$ of the $\operatorname{Inh}^{\mathrm{r}}$ strains in this study had no mutation at $k a t G$ codon 315 , it is likely that mutations in other genes, such as the inhA locus, significantly contribute to resistance. Previous studies have shown that mutations in the upstream region of the inhA locus result in increased levels of InhA (NADH-dependent enoyl-acyl carrier protein reductase) expression, thereby elevating the drug target levels and producing INH resistance via a titration mechanism (16). We searched for mutations in the inhA regulatory region of $26 \mathrm{Inh}^{\mathrm{r}}$ M. tuberculosis strains with a wt codon 315 in kat $G$ and found a substitution at position 15 upstream of the start codon in 12 $(14.5 \%)$ isolates. This frequency was similar to the $13.5 \%$ frequency in strains from Lithuania (2) but higher than the $4.3 \%$ frequency in strains from Seville, Spain (24). Since a polymorphism in the inh $A$ regulatory region accounted for almost $15 \%$ of all $\mathrm{Inh}^{\mathrm{r}}$ strains examined in this study, we suggest screening for such a polymorphism in all isolates from Poland that have no detectable changes at codon 315 of the kat $G$ gene. Fourteen $(16.5 \%)$ strains showed a lack of mutations in both the kat $G$ gene and the $i n h A$ locus fragments analyzed here. According to previous studies, there are some 18 additional genes that have been implicated in INH resistance, including $k a s A, n d h$, and the $\operatorname{oxy} R$-ahpC intergenic region (17). These genes either are involved in mycolic acid biosynthesis or are overexpressed as a response to the buildup or cellular toxicity of INH. Therefore, the alterations responsible for INH resistance in these 14 strains may be associated with any of these loci.

The prevalence of $\mathrm{Rmp}^{\mathrm{r}}$ mutations within the $r p o B$ core region $(97 \%)$ as well as $\operatorname{Inh}^{\mathrm{r}}$ mutations at kat $G$ codon 315 and the inh $A$ locus (69 and $14.5 \%$, respectively) in $M$. tuberculosis strains from Poland indicated the potential for a rapid diagnostic test for the detection of drug-resistant TB. Different genotypic assays have been proposed for the detection of mutations involved in drug resistance in M. tuberculosis, including a recent real-time PCR assay coupled to fluorescence detection. Formats that utilize molecular beacons (6) and biprobes (5) for the detection of RMP resistance have been reported. 
However, as many as five different beacons are required to encompass the entire $r p o B$ core region, and three biprobes described by Edwards et al. (5) detected mutations in only four codons of the $r p o B$ gene. We evaluated a standard FRET probe set that was previously described by Torres et al. (25) for the detection of $\mathrm{Rmp}^{\mathrm{r}}$ mutations at codons 526 and 531 of the $r p o B$ gene and the RPO1 dual-sensor FRET probes that were recently described by García de Viedma et al. (7) to detect changes in the $5^{\prime}$ region of the rpoB core. Using both probe sets, we were able to detect all 17 different mutations in nine different codons. The majority of these alterations were not represented in previous reports $(7,25)$, thus further proving the efficiency of the method.

Also, the INH probe (TB sensor) utilized by Torres et al. (25) proved to be efficient for detecting mutations at $\mathrm{katG}$ codon 315 . Using this probe, we were able to detect not only the previously described substitutions (ACC and AAC) but also three additional changes (ACT, ACA, and ATC) that were not present in the authors' collection. Analysis of the melting profiles of the three probes allowed the determination of the codon positions of mutations or even the distinction of different nucleotide substitutions at the same codon. As an alternative to FRET probes, we propose a set of three TaqMan MGB probes designed to detect the wt sequence AGC and the two most frequent substitutions, ACC and ACA. These short oligonucleotides are perfectly suited to search for mutations at a particular position, as in the case of katG codon 315. Compared to FRET probes, the TaqMan MGB probes offer the advantage of detecting a particular mutation that may have further implications, since different mutations may be associated with different levels of resistance.

Since almost $15 \%$ of the strains studied had a $\mathrm{C} \rightarrow \mathrm{T}$ nucleotide substitution at position 15 upstream of the start site of the inh $A$ gene, we applied a pair of standard FRET probes to search for mutations in the regulatory region of $\operatorname{inh} A$ (26). Mutations in this region cause the overexpression of this gene. The inh $A$-specific probe sequence was designed to bind to a mutant sequence at position -15 in the putative promoter site (A instead of C). In all cases, the $T_{m} \mathrm{~s}$ for the mutants were ca. $5^{\circ} \mathrm{C}$ higher than the $T_{m}$ for the wt reference strain, proving this test efficient for detecting mutations in the regulatory region of $\operatorname{inh} A$. We emphasize that in all cases studied, the results obtained by real-time PCR amplification corresponded to the nucleotide sequence data.

In the present study, we determined the occurrence and frequencies of different kinds of mutations at various target loci in drug-resistant clinical isolates of M. tuberculosis from Poland. We developed a basis for the detection of mutations underlying RMP and INH resistance in M. tuberculosis in Poland by the application of real-time PCR technology. This molecular method is fast and reliable and could be directly applied for examinations of clinical material.

\section{ACKNOWLEDGMENTS}

The work performed in Poland was supported by grants from the State Committee for Scientific Research (KBN, contract no. PBZ030-15 and 3P04C06825). A.S. was supported by a DAAD (Deutscher Akademischer Austauschdienst) Fellowship at the Forschungszentrum Borstel, Borstel, Germany.
We thank Olfert Landt (TIB MOLBIOL SyntheseLabor, Berlin, Germany) for designing the primers and FRET probes and for providing us with some of these as a gift for testing.

\section{REFERENCES}

1. Augustynowicz-Kopec, E., Z. Zwolska, A. Jaworski, E. Kostrzewa, and M. Klatt. 2003. Drug-resistant tuberculosis in Poland in 2000: second national survey and comparison with the 1997 survey. Int. J. Tuberc. Lung Dis. $7: 645-651$

2. Bakonyte, D., A. Baranauskaite, J. Cicenaite, A. Sosnovskaja, and P. Stakenas. 2003. Molecular characterization of isoniazid-resistant Mycobacterium tuberculosis clinical isolates in Lithuania. Antimicrob. Agents Chemother. 47:2009-2011.

3. Bártfai, Z., Á. Somoskövi, C. Ködmön, N. Szabó, E. Puskás, L. Kosztolányi, E. Faragó, J. Mester, L. M. Parsons, and M. Salfinger. 2001. Molecular characterization of rifampin-resistant isolates of Mycobacterium tuberculosis from Hungary by DNA sequencing and the line probe assay. J. Clin. Microbiol. 39:3736-3739.

4. Cavusoglu, C., S. Hilmioglu, S. Guneri, and A. Bilgic. 2002. Characterization of $r p o B$ mutations in rifampin-resistant clinical isolates of Mycobacterium tuberculosis from Turkey by DNA sequencing and line probe assay. J. Clin. Microbiol. 40:4435-4438.

5. Edwards, K. J., L. A. Metherell, M. Yates, and N. A. Saunders. 2001 Detection of $r p o B$ mutations in Mycobacterium tuberculosis by biprobe analysis. J. Clin. Microbiol. 39:3350-3352.

6. El-Hajj, H. H., S. A. E. Marras, S. Tyagi, F. R. Kramer, and D. Alland. 2001 Detection of rifampin resistance in Mycobacterium tuberculosis in a single tube with molecular beacons. J. Clin. Microbiol. 39:4131-4137.

7. García de Viedma, D., M. del Sol Diaz Infantes, F. Lasala, F. Chaves, L. Alcalá, and E. Bouza. 2002. New real-time PCR able to detect in a single tube multiple rifampin resistance mutations and high-level isoniazid resistance mutations in Mycobacterium tuberculosis. J. Clin. Microbiol. 40:988995.

8. Gonzalez, N., M. J. Torres, J. Aznar, and J. C. Palomares. 1999. Molecular analysis of rifampin and isoniazid resistance of Mycobacterium tuberculosis clinical isolates in Seville, Spain. Tuber. Lung Dis. 79:187-190.

9. Heep, M., U. Rieger, D. Beck, and N. Lehn. 2000. Mutations in the beginning of the $r p o B$ gene can induce resistance to rifamycins both in Helicobacter pylori and Mycobacterium tuberculosis. Antimicrob. Agents Chemother. 44: 1075-1077.

10. Heep, M., B. Brandtstätter, U. Rieger, N. Lehn, E. Richter, S. Rüsch-Gerdes, and S. Niemann. 2001. Frequency of rpoB mutations inside and outside the cluster I region in rifampin-resistant clinical Mycobacterium tuberculosis isolates. J. Clin. Microbiol. 39:107-110.

11. Kamerbeek, J., L. Schouls, A. Kolk, M. van Agterveld, D. van Soolingen, S. Kuijper, A. Bunschoten, H. Molhuizen, R. Shaw, M. Goyal, and J. D. A. van Embden. 1997. Simultaneous detection and strain differentiation of $\mathrm{Myco}$ bacterium tuberculosis for diagnosis and epidemiology. J. Clin. Microbiol. 35:907-914.

12. Mdluli, K., D. R. Sherman, M. J. Hickey, B. N. Kreiswirth, S. Morris, C. K. Stover, and C. E. Barry III. 1996. Biochemical and genetic data suggest that InhA is not the primary target for activated isoniazid in Mycobacterium tuberculosis. J. Infect. Dis. 174:1085-1090.

13. Mokrousov, I., O. Narvskaya, T. Otten, E. Limeschenko, L. Steklova, and B. Vyshnevkiy. 2002. High prevalence of KatG Ser315Thr substitution among isoniazid-resistant Mycobacterium tuberculosis clinical isolates from Northwestern Russia, 1996 to 2001. Antimicrob. Agents Chemother. 46:14171424.

14. Morcillo, N., M. Zumarraga, A. Alito, A. Dolmann, L. Schouls, A. Cataldi, K. Kremer, and D. van Soolingen. 2002. A low-cost, home-made, reverse-line blot hybridisation assay for rapid detection of rifampicin resistance in $M y$ cobacterium tuberculosis. Int. J. Tuberc. Lung Dis. 6:959-965.

15. Qian, L., C. Abe, T.-P. Lin, M.-C. Yu, S.-N. Cho, S. Wang, and J. T. Douglas. 2002. rpoB genotypes of Mycobacterium tuberculosis Beijing family isolates from East Asian countries. J. Clin. Microbiol. 40:1091-1094.

16. Ramaswamy, S., and J. M. Musser. 1998. Molecular genetic basis of antimicrobial agent resistance in Mycobacterium tuberculosis: 1998 update. Tuber. Lung Dis. 79:3-29.

17. Ramaswamy, S. V., R. Reich, S.-J. Dou, L. Jasperse, X. Pan, A. Wanger, T. Quitugua, and E. A. Graviss. 2003. Single nucleotide polymorphisms in genes associated with isoniazid resistance in Mycobacterium tuberculosis. Antimicrob. Agents Chemother. 47:1241-1250.

18. Rattan, A., A. Kalia, and N. Ahmad. 1998. Multidrug-resistant Mycobacterium tuberculosis: molecular perspectives. Emerg. Infect. Dis. 4:195-209.

19. Sarýbab, Z., T. Kocagöz, A. Alp, and A. Günalp. 2003. Rapid detection of rifampin resistance in Mycobacterium tuberculosis isolates by heteroduplex analysis and determination of rifamycin cross-resistance in rifampin-resistant isolates. J. Clin. Microbiol. 41:816-818.

20. Siddiqi, N., M. Shamim, S. Hussain, R. K. Choudhary, N. Ahmed, Prachee, S. Banerjee, G. R. Savithri, M. Alam, N. Pathak, A. Amin, M. Hanief, V. M. Katoch, S. K. Sharma, and S. E. Hasnain. 2002. Molecular characterization 
of multidrug-resistant isolates of Mycobacterium tuberculosis from patients in North India. Antimicrob. Agents Chemother. 46:443-450.

21. Slayden, R. A., and C. E. Barry III. 2000. The genetics and biochemistry of isoniazid resistance in Mycobacterium tuberculosis. Microbes Infect. 2:659669.

22. Telenti, A., N. Honoré, C. Bernasconi, J. March, A. Ortega, H. E. Takiff, and S. T. Cole. 1997. Genotyping assessment of isoniazid and rifampin resistance in Mycobacterium tuberculosis: a blind study at reference laboratory level. J. Clin. Microbiol. 35:719-723.

23. Telenti, A., P. Imboden, F. Marchesi, D. Lowrie, S. Cole, M. J. Colston, L. Matter, K. Schopfer, and T. Bodmer. 1993. Detection of rifampicin-resistance mutations in Mycobacterium tuberculosis. Lancet 431:647-650.

24. Torres, M. J., A. Criado, N. Gonzalez, J. C. Palomares, and J. Aznar. 2002 Rifampin and isoniazid resistance associated mutations in Mycobacterium tuberculosis clinical isolates in Seville, Spain. Int. J. Tuberc. Lung Dis. 6:160163.

25. Torres, M. J., A. Criado, J. C. Palomares, and J. Aznar. 2000. Use of real-time PCR and fluorimetry for rapid detection of rifampin and isoniazid resistance-associated mutations in Mycobacterium tuberculosis. J. Clin. Microbiol. 38:3194-3199.

26. Torres, M. J., A. Criado, J. C. Palomares, and J. Aznar. 2002. Rapid detection of resistance associated mutations in Mycobacterium tuberculosis by LightCycler PCR, p. 83-91. In U. Reischl, C. Wittwer, and F. Cockerill (ed.), Rapid cycle real time PCR-methods and applications. Springer Press, Heidelberg, Germany.

27. Tracevska, T., I. Jansone, L. Broka, O. Marga, and V. Baumanis. 2002 Mutations in the rpoB and katG genes leading to drug resistance in $\mathrm{Myco}$ bacterium tuberculosis in Latvia. J. Clin. Microbiol. 40:3789-3792.

28. van Embden, J. D., M. D. Cave, J. T. Crawford, J. W. Dale, K. D. Eisenach, B. Gicquel, P. Hermans, C. Martin, R. McAdam, and T. M. Shinnick. 1993. Strain identification of Mycobacterium tuberculosis by DNA fingerprinting: recommendations for a standardized methodology. J. Clin. Microbiol. 31: 406-409.

29. World Health Organization. 1998. The world health report. Life in the 21st century. A vision for all. World Health Organization, Geneva, Switzerland 